\title{
Isolation and Molecular Characterization of Mycoplasma Isolates from Pneumonic Sheep and Goats in Andhra Pradesh
}

\author{
B. Monika Yadav ${ }^{1}$, S. Vijaya Lakshmi ${ }^{*}$, N. Vinod Kumar ${ }^{3}$ and A. Jagadeesh Babu ${ }^{4}$ \\ ${ }^{1}$ Veterinary Assistant Surgeon, Nagalapuram Chittoor (dt), AP, India \\ ${ }^{2}$ LRS, Palamaneru, SVVU, India \\ ${ }^{3}$ Department of Microbiology, CVSc, Tirupati, India \\ ${ }^{4}$ Department of Veterinary Public health \& Epidemiology, CVSc, Tirupati, India
}

*Corresponding author

\section{A B S T R A C T}

\section{Ke y w o r d s \\ Pneumonic sheep and goats, Mycoplasma \\ Article Info \\ Accepted: \\ 12 August 2020 \\ Available Online: \\ 10 September}

\begin{abstract}
In the present study, attempts for the isolation of Mycoplasma organisms were carried out in PPLO broth and PPLO agar medium. Out of 253 sheep and 112 goat nasal swab samples inoculated in PPLO broth, 27 sheep and 14 goat samples showed colour change in broth. Upon sub-culturing of 27 sheep and 14 goat broth nasal swab samples on PPLO agar, 17 sheep and 9 goat samples produced colonies. Positive samples produced yellow color change to broth medium with mild turbidity after $48 \mathrm{hrs}$ of incubation at $37^{\circ} \mathrm{C}$ in $\mathrm{CO}_{2}$ incubator maintaining $5 \% \mathrm{CO}_{2}$. After 7 th day of incubation on PPLO agar, the agar plates showed fried egg colonies and granular colonies when examined under 10X magnification of microscope. Further Mycoplasma isolation was confirmed by PCR targeting 16S $r$ RNA gene of genus Mycoplasma and Mycoplasma ovipneumoniae.
\end{abstract}

\section{Introduction}

Mycoplasmas are the smallest prokaryotic cells capable of self-replication and are pleomorphic organisms ranging from spherical ( 0.3 to 0.9 picomole in diameter) to filamentous (up to 1.0 picomole long). Mycoplasmas lack cell wall and have flexible triple layered cell membrane which allows them to pass through bacterial membrane filters of pore size 0.22 to $0.45 \mu \mathrm{m}$ (Quinn et al., 1994). The Mycoplasma genome consists of small circular double stranded DNA molecule of $580-2220 \mathrm{~kb}$ size. These are largely extracellular parasites on mucous membranes of animals (Razin et al., 1998). Mycoplasmas are fastidious in nature, hence it is very difficult to grow Mycoplasma on ordinary laboratory media. Sterol (cholesterol) and fatty acids are essential components for the growth of Mycoplasma spp. Therefore, some special media are being used for the growth and isolation of different pathogenic Mycoplasma spp. Mycoplasma can grow on media enriched with some special components like beef heart infusion, 
peptone, yeast extract and animal serum @ 5$20 \%$ with various supplements (Thiaucourt et al., 1992; Nicholas, 2002). Pleuro pneumonia like organism (PPLO) broth and modified Hay media are commonly used for the isolation and culturing of various Mycoplasma spp. by many researchers (Noah et al., 2011; Ongor et al., 2011; Sadique et al., 2012; Kabir and Bari, 2015). Chakraborty et $a l$. , (2014) suggested adding thallium acetate, fluconazole and penicillin in the media to prevent bacterial and fungal contamination. The present study aimed at isolation and identification of Mycoplasmas by culturing nasal swabs and lung samples collected from sheep and goats with respiratory symptoms on PPLO broth and PPLO agar plates.

\section{Materials and Methods}

\section{Sample collection}

Nasal swabs from 253 sheep and 112 goats showing respiratory symptoms of nasal discharge, coughing and sneezing were collected and this was transferred into a sterile micro centrifuge tube containing PPLO broth and brought to the laboratory over ice maintaining cold chain. The samples were immediately incubated at $37^{\circ} \mathrm{C}$ in $\mathrm{CO} 2$ incubator maintaining 5\% $\mathrm{CO} 2$ for 48 hours.

\section{Preparation of PPLO (Mycoplasma) broth}

PPLO (Mycoplasma) broth was prepared as per the manufacturer guidelines. 2.1gm of PPLO broth base media was added in $70 \mathrm{ml}$ of double distilled water in a conical flask. Then medium was autoclaved at $15 \mathrm{lbs}$ pressure at $121^{\circ} \mathrm{C}$ for $15 \mathrm{~min}$. After autoclaving the media was allowed to cool down to $45^{\circ} \mathrm{C}$ and then one vial $(20 \mathrm{ml})$ of mycoplasma enrichment supplement was added mixed well and dispensed aseptically into sterile microcentrifuge tubes and stored at $4^{\circ} \mathrm{C}$ for further use.

\section{Preparation of PPLO (Mycoplasma) agar}

PPLO (Mycoplasma) agar was prepared as per the manufacturer guidelines. $3.6 \mathrm{gm}$ of mycoplasma agar base along with $0.8 \mathrm{gm}$ of agar was dissolved in $70 \mathrm{ml}$ of double distilled water in a conical flask. Then medium was autoclaved at $15 \mathrm{lbs}$ pressure at $121^{\circ} \mathrm{C}$ for $15 \mathrm{~min}$. After autoclaving the media was allowed to cool down to $45^{\circ} \mathrm{C}$ and then one vial $(20 \mathrm{ml})$ of Mycoplasma enrichment supplement was added and mixed well. Then the media was poured into Petri plates and were stored at $4^{\circ} \mathrm{C}$ after setting.

\section{Inoculation}

Nasal swabs and lung tissue samples collected from sheep and goats suspected for Mycoplasmosis in PPLO broth medium were incubated at $37^{\circ} \mathrm{C}$ in $\mathrm{CO} 2$ incubator maintaining $5 \% \quad \mathrm{CO} 2$ for 2 days. The incubated microcentrifuge tubes were examined daily for presence of mass turbidity and change in color. The positive growths were sub-cultured on PPLO agar media by spreading a few drops of sample or by making a direct impression with the cut surface of lung lesion without spreading. After subculturing onto PPLO agar medium, the Petri plates were incubated at $37^{\circ} \mathrm{C}$ in $\mathrm{CO} 2$ incubator maintaining 5\% $\mathrm{CO} 2$ for $10-15$ days.

PCR for detection of genus Mycoplasma and Mycoplasma ovipneumonia

PCR for detection of $16 \mathrm{~S}$ rRNA gene of genus Mycoplasma and Mycoplasma ovipneumonia was carried out as per the method of Cetinkya et al., (2009) and McAuliffe et al., (2003) respectively.

\section{Primers}

The oligonucleotide primers were procured from Sigma Aldrich India Pvt. Ltd., 
Bangalore. Details of the primer sequence are enlisted in Table $1 \& 2$. Working solutions were prepared from original stock (100 $\mathrm{pmol} / \mu \mathrm{l})$ in nuclease free water at $10 \mathrm{pmol} / \mu \mathrm{l}$. The reaction mixture consists of Taq buffer A (10X) - $2.5 \mu \mathrm{l}, \mathrm{MgCl} 2(25 \mathrm{mM})-1.5 \mu \mathrm{l}$, dNTP $\operatorname{mix}(10 \mathrm{mM})-0.5 \mu \mathrm{l}$, Taq DNA Polymerase $(1 \mathrm{U} / \mu \mathrm{l})-1.0 \mu \mathrm{l}$, Forward primer $(10 \mathrm{pmol} / \mu \mathrm{l})$ $1.0 \mu \mathrm{l}$, Reverse primer $(10 \mathrm{pmol} / \mu \mathrm{l})-1.0 \mu \mathrm{l}$, Template DNA - 5.0 $\mu 1$, Nuclease free water 12.5 $\mu$. The tubes were then spun for $10 \mathrm{sec}$ and PCR was carried out in Thermal cycler (Eppendorf Pvt. Ltd., Hamburg, Germany). Cyclic conditions used for amplification of Mycoplasma and Mycoplasma ovipneumoniae are given in detail in Table $3 \& 4$.

Agarose gel electrophoresis of PCR product in $2 \%$ agarose

Amplified products were analysed by agarose gel electrophoresis in 2\% agarose gels in TBE buffer (appendix) containing ethidium bromide at 60 volts for 90 min to detect PCR amplified product of genus Mycoplasma and Mycoplasma ovipneumoniae targeting $16 \mathrm{~S}$ $r$ RNA. The gels were viewed under UV transilluminator and photographed with gel documentation system (AlphaInnotech, Alphaimager HP).

\section{Results and Discussion}

Out of 253 sheep and 112 goat nasal swab samples inoculated in PPLO broth, 27 sheep and 14 goat samples showed colour change in broth. Upon sub-culturing of 27 sheep and 14 goat broth nasal swab samples on PPLO agar, 17 sheep and 9 goat samples produced colonies.

\section{Growth in mycoplasmal (PPLO) broth}

Mycoplasma suspected samples from sheep and goat were inoculated in PPLO broth and positive samples produced mild turbidity with yellow colour change in broth medium after $48 \mathrm{hr}$ of incubation indicating multiplication of organisms (Fig. 1). The growth was generally seen at the bottom of the tubes and produced a whirlpool like structure when the tubes were slightly agitated.

Table.1 Primers used for detection of 16S $r$ RNA gene of genus Mycoplasma

\begin{tabular}{|l|l|l|c|}
\hline \multicolumn{1}{|c|}{ Primers } & \multicolumn{1}{|c|}{ Primer Name } & \multicolumn{1}{|c|}{ Nucleotide Sequence } & Amplicn Size \\
\hline $\begin{array}{l}\text { Mycoplasma } \\
\text { genus specific } \\
\text { primer (Cetinkya } \\
\text { et al., 2009) }\end{array}$ & GPO3F & $\begin{array}{l}\text { 5'-TGGGGAGCAAACAGGATTAGA } \\
\text { TACC-3' }\end{array}$ & $\mathbf{2 8 0}$ bp \\
\hline
\end{tabular}

Table.2 Primers used for detection of Mycoplasma ovipneumoniae

\begin{tabular}{|l|l|l|c|}
\hline \multicolumn{1}{|c|}{ Primers } & \multicolumn{1}{c|}{ Primer Name } & \multicolumn{1}{c|}{ Nucleotide Sequence } & Amplicon Size \\
\hline $\begin{array}{l}\text { Mycoplasma } \\
\text { ovipneumoniae } \\
\text { (McAuliffe } \text { et } \\
\text { al., 2003) }\end{array}$ & LMF1 & 5'-TGAACGGAATATGTTAGCTT-3' & 361 bp \\
\hline
\end{tabular}


Table.3 Cyclic conditions used for amplification of 16S $r$ RNA gene of genus Mycoplasma

\begin{tabular}{|c|l|c|c|}
\hline S.No & \multicolumn{1}{|c|}{ Temperature $\left({ }^{\mathbf{0}} \mathbf{C}\right)$} & Duration & No. of cycles \\
\hline $\mathbf{1 .}$ & 94 (initial denaturation) & $4 \mathrm{~min}$ & $\mathbf{1}$ \\
\hline $\mathbf{2 .}$ & 94 (denaturation) & $30 \mathrm{sec}$ & $\mathbf{3 5}$ \\
\hline $\mathbf{3 .}$ & 56 (annealing) & $30 \mathrm{sec}$ & \\
\hline $\mathbf{4 .}$ & 72 (extension) & $30 \mathrm{sec}$ & \\
\hline $\mathbf{5 .}$ & $\mathbf{7 2}$ (final extension) & $\mathbf{1 0 ~} \mathbf{~ m i n}$ & $\mathbf{1}$ \\
\hline
\end{tabular}

Table.4 Cyclic conditions for amplification of Mycoplasma ovipneumoniae

\begin{tabular}{|c|l|c|c|}
\hline S.No & \multicolumn{1}{|c|}{ Temperature $\left({ }^{\mathbf{}} \mathbf{C}\right)$} & Duration & No. of cycles \\
\hline $\mathbf{1 .}$ & 94 (initial denaturation) & $5 \mathrm{~min}$ & $\mathbf{1}$ \\
\hline $\mathbf{2 .}$ & 94 (denaturation) & $30 \mathrm{sec}$ & $\mathbf{3 0}$ \\
\cline { 1 - 3 } $\mathbf{3 .}$ & 55 (annealing) & $30 \mathrm{sec}$ & \\
\hline $\mathbf{4 .}$ & 72 (extension) & $30 \mathrm{sec}$ & \\
\hline $\mathbf{5 .}$ & $\mathbf{7 2}$ (final extension) & $\mathbf{7 ~} \mathbf{m i n}$ & $\mathbf{1}$ \\
\hline
\end{tabular}

Fig.1 Colour change in PPLO broth inoculated with nasal swab after 48 h of incubation

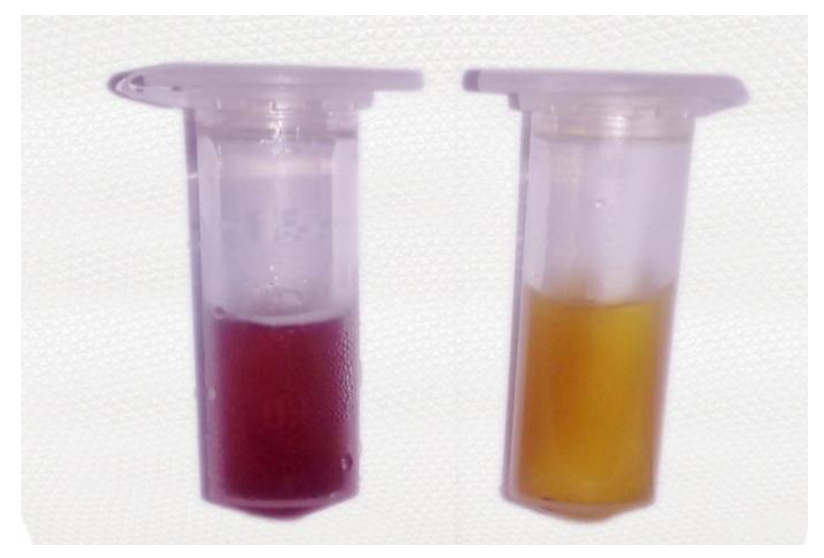

Fig.2 Typical fried egg colony of Mycoplasma

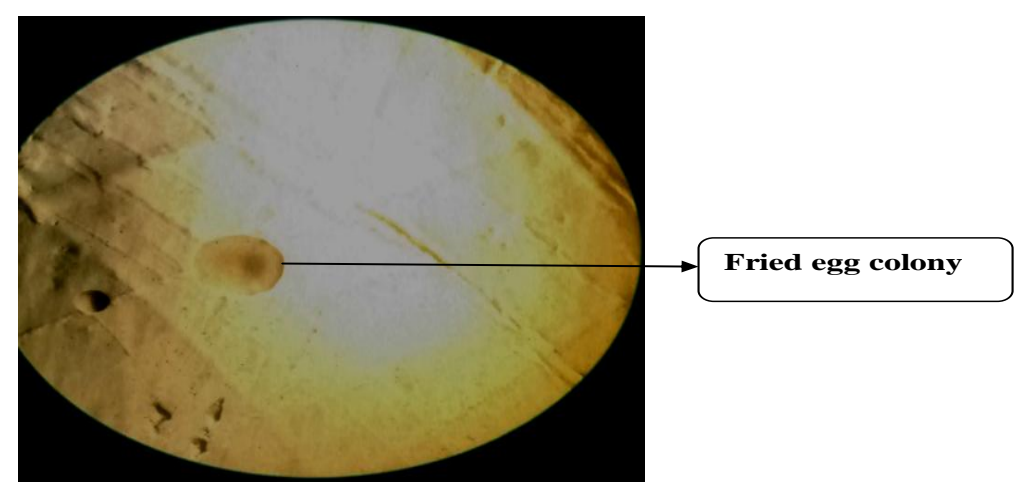


Fig.3 Granular colonies of Mycoplasma ovipneumoniae

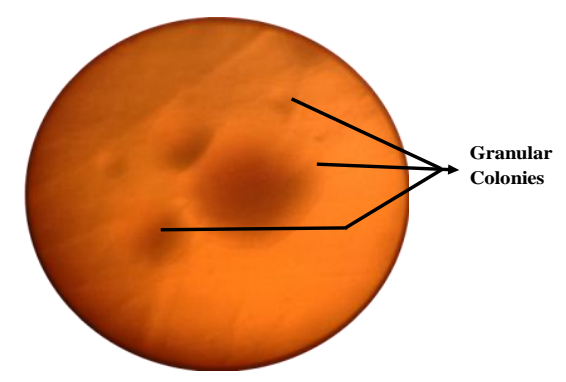

Fig.4 Amplification of 16S rRNA gene of genus Mycoplasma from clinical cases of respiratory infections in sheep and goats

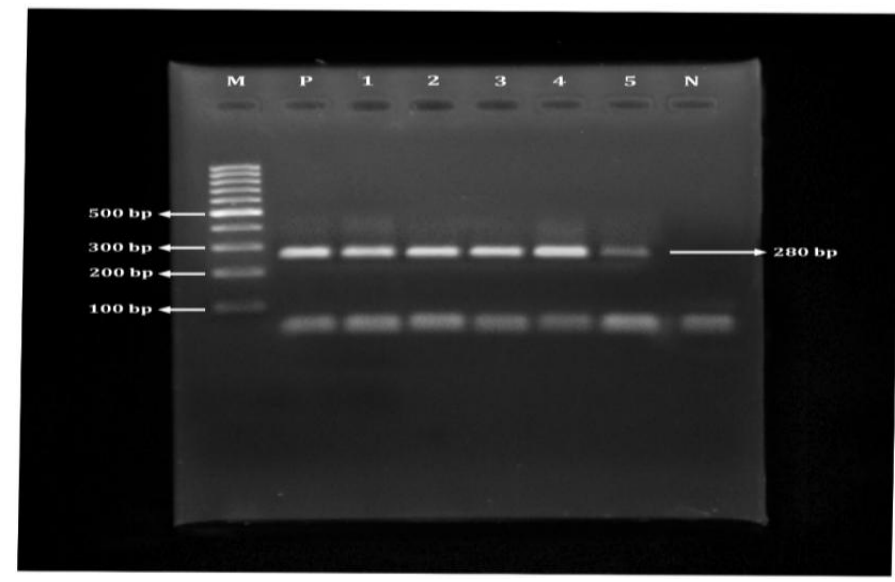

LaneM

Ladder (100 bp)

LaneP : $\quad$ Positive Control

Lane1,2,3,4 \& 5: $\quad$ Field samples positive for 16S rRNA gene of genus Mycoplasma LaneN : Negative Control

Fig.5 Amplification of 16S rRNA gene PCR for of Mycoplasma ovipneumoniae from clinical cases of respiratory infections in sheep and goats

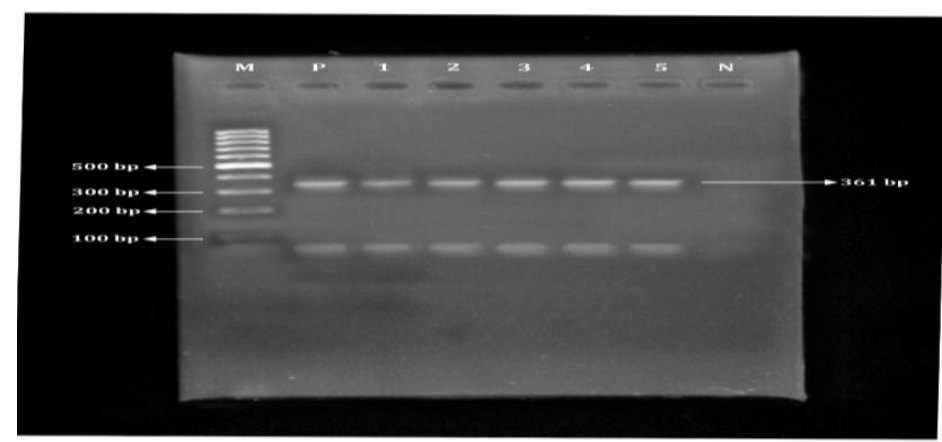

Lane $\mathrm{M} \quad$ : Ladder (100 bp)

Lane P : $\quad$ Positive Control

Lane 1,2,3,4 \& $5 \quad$ : Field samples positive for $16 \mathrm{~S} r \mathrm{RNA}$ gene Mycoplasma ovipneumoniae

LaneN : Negative Control 


\section{Growth on mycoplasmal (PPLO) agar}

The suspected growths of Mycoplasma from broth culture were inoculated on to PPLO agar plates. Isolates started producing colonies three to four days after inoculation on Mycoplasma agar. Colonies were observed after 7th day of incubation. Petri plates were observed under microscope (10X) to study the colony characteristics of various Mycoplasma isolates. Mycoplasma colonies exhibited a typical fried-egg appearance (Fig. 2). Along with the fried egg colonies, granular colonies of Mycoplasma without central nipple (Fig. 3) was observed which may be suggestive of Mycoplasma ovipneumoniae colonies.

\section{Confirmation of Mycoplasmal colonies by PCR targeting 16sRNA gene of genus Mycoplasma and Mycoplasma ovipneumonia}

DNA extracted from colonies were subjected to PCR for confirmation. Out of 17 sheep and 9 goat samples which produced colonies on PPLO agar, all yielded 280bp long sequence of 16S rRNA gene of Mycoplasma (Fig. 4). Only 4 sheep and 1 goat sample colonies yielded $361 \mathrm{bp}$ long sequence of $16 \mathrm{~S} r \mathrm{RNA}$ gene of Mycoplasma ovipneumoniae (Fig. 5).

In the present study, attempts for the isolation of Mycoplasma organisms was carried out in PPLO broth and PPLO agar medium. After $48 \mathrm{hr}$ of incubation, the positive samples produced yellow colour change to broth medium with mild turbidity. The findings were in accordance with the earlier reports of Kumar et al., (2012) wherein, his studies observed change in colour of PPLO broth with mild turbidity after $48 \mathrm{hr}$ of incubation. Kumar et al., (2013) in their studies reported that out of 171 clinical samples, 45 samples showed fine turbidity and $\mathrm{PH}$ shift (acidic) imparting a yellow colour to medium within 3 to 10 days indicating Mycoplasma growth.
After $72 \mathrm{hr}$ of incubation, PPLO broth was streaked across the surface of PPLO agar plate and incubated at $37^{\circ} \mathrm{C}$ with $5 \% \mathrm{CO} 2$ in $\mathrm{CO} 2$ incubator for 10-15 days. After 7th day of incubation, the agar plates were examined under 10X magnification of microscope for colony morphology. In the present study, two types of colonies were observed. One type of colonies was circular, convex giving fried egg appearance with central part of colonies darker than periphery. Other type of colonies were, granular without central nipple. Similar findings were observed by Kumar et al., (2012) after 48 hrs of incubation on PPLO agar plate, it produced small size, circular, convex colonies with central part of colonies darker than periphery. McAuliffe et al., (2005) in his studies observed colonies with fried egg appearance typical for many mycoplasma and center less granular colonies were seen on solid medium after 4 to 6 days of incubation and were identified by DGGE in mixed culture as Mycoplasma ovipneumoniae.

\section{References}

Çetinkaya B, Kalin R, Karahan M, Atil E, Manso Silván $\mathrm{L}$ and Thiaucourt $\mathrm{F}$ 2009 Detection of contagious caprine pleuropneumonia in East Turkey. Review of Scientific Technology. 28: 1037-1044.

Chakraborty S, Kumar A, Tiwari R, Rahal A, Malik Y, Dhama K, Pal A and Prasad M 2014 Advances in diagnosis of respiratory diseases of small ruminants. Veterinary Medicine International 2014: 508304. DOI: http://dx.doi.org/10.1155/2014/508304

Kabir M H and Bari A S 2015 Isolation and identification of Mycoplasma from respiratory system of goat. Microbiology Research International. 3(2): 20-26.

Kumar A, Verma A K, Gangwar N and Rahal 
A 2012 Isolaion, characterization and antibiogram of Mycoplasma bovis in sheep pneumonia. Asian Journal of Animal and Veterinary Advances. 7(2): 149-157.

Kumar V, Rana R, Mehra S and Rout P K 2013 Isolation and Characterization of Mycoplasma mycoides subspecies capri from Milk of Natural Goat Mastitis Cases. ISRN veterinary science. Volume 2013, Article ID 593029, 5 pages http://dx.doi.org/10.1155/2013/593029

McAuliffe L, Ellis R J, Ayling R D and Nicholas R A J 2003 Differentiation of Mycoplasma species by $16 \mathrm{~s}$ ribosomal DNA PCR and denaturing gradient gel electrophoresis fingerprinting. Journal of Clinical Microbiology. 41: 4844-4847.

McAuliffe L, Ellis R J, Lawes J R, Ayling R D and Nicholas R A J 2005 16S rDNA PCR and DGGE, a single generic test for detecting and differentiating Mycoplasma species. Journal of Medical Microbiology. 54: 1-9.

Nicholas R A J 2002 Improvements in the diagnosis and control of diseases of small ruminants caused by mycoplasmas. Small Ruminant Research. 45: 145-149.

Noah EY, Kusiluka LM J, Wambura P and Kimera S I 2011 Field Isolation of
Mycoplasma capripneumoniae in Central Zone of Tanzania. International Journal of Animal and Veterinary Advances. 3(6): 434-442.

Ongor H, Kalin R and Acik M N 2011 Detection of Mycoplasma ovipneumoniae from goats with nasal discharge by culture and polymerase chain reaction. Pakisthan Veterinary Journal. 31(3): 244-248.

Quinn P J, Carter M E, Markey B K and Carter G R 1994 Clinical Veterinary Microbiology. Pp. 320-326. Wolf Publishing, Mosby Co. U.S.A.

Razin S, Yogev D and Naot Y 1998 Molecular biology and pathogenicity of mycoplasmas. Microbiology and Molecular Biology Reviews. 62: 10941156.

Sadique U, Zafer R, Younas Z, Hassan U, Idrees M, Mushtaq M, Sajid A and Sabtain M $2012 \quad$ Molecular characterization of contagious caprine pleuropneumonia (CCPP) in small ruminants of Khyber Pakhtunkhwa. Pakisthan Journal of Animal and Plant Sciences. 22: 33-37.

Thiaucourt F, Guérin C, Mady V and Lefèvre P C 1992 Diagnosis of caprine contagious pleuropneumonia: recent improvements. Review of Scientific Technology. 11(3): 859-865.

\section{How to cite this article:}

Monika Yadav, B., S. Vijaya Lakshmi, N. Vinod Kumar and Jagadeesh Babu, A. 2020. Isolation and Molecular Characterization of Mycoplasma Isolates from Pneumonic Sheep and Goats in Andhra Pradesh. Int.J.Curr.Microbiol.App.Sci. 9(09): 1608-1614. doi: https://doi.org/10.20546/ijcmas.2020.909.200 